\title{
Determination of the Pesticide Carbaryl by Microemulsion Room-Temperature Phosphorescence in Real Samples
}

\author{
Antonio Segura Carretero, Carmen Cruces Blanco ${ }^{\dagger}$ \\ and Alberto Fernández Gutiérrez \\ Department of Analytical Chemistry, Faculty of Sciences, University of Granada, \\ E-18071 Granada, Spain
}

\begin{abstract}
A room-temperature phosphorescence method for the determination of the pesticide carbaryl is described. The proposed method is based on the formation of a microemulsion obtained by mixing an apolar solvent with the surfactant sodium dodecyl sulfate as the micellar medium in the presence of thallium nitrate as the external heavy atom salt. To avoid the oxygen quenching, a sodium sulfite solution was used. A complete and exhaustive statistical analysis of experimental data by a multivariate optimization approach was performed to establish the optimum experimental variables. Good results have been obtained when the insecticide have been analyzed in synthetic and real samples.
\end{abstract}

Keywords Room-temperature phosphorescence, microemulsion, experimental design, carbaryl

The group of commercial insecticides known as carbamates have increased in popularity during the years as a consequence of their selective insecticidal properties, low mammalian toxicity and lack of undue persistence.

A great number of analytical methods have been proposed in the literature for the determination of this insecticide in numerous matrices by different instrumental methods ${ }^{1-9}$, mainly spectrophotometric and spectrofluorometric (Table 1).

Micelle-stabilized room temperature phosphorescence (MS-RTP) is a type of RTP in solution first reported by Kalyanasundaram et al..$^{10}$ which has been developed by several authors during the last decade. ${ }^{11-13}$ In all these works, a dramatic enhancement of RTP signals has been observed when the phosphors are incorporated into the micellar assembly. However, deoxygenation is needed in all cases and the traditional MS-RTP method of using $\mathrm{N}_{2}$ purging to remove oxygen from solution, which is limited in application because of foam generation and other concomitant problems, has been recently replaced by a method proposed by Díaz-García and Sanz-Medel ${ }^{14}$ based on a chemical deoxygenation with sodium sulfite, which represents a great technical advance in the use of MS-RTP.

MS-RTP suffers from a limitation due to the slow dissolution of apolar analytes in the aqueous micellar solutions. Many polycyclic aromatic hydrocarbons (PAHs) have been determined by this technique; ${ }^{15-17}$ not only is the procedure for preparing samples relatively

\footnotetext{
† To whom correspondence should be addressed.
}

time consuming, but also the solubilizing capability of micelle solutions for some PAHs with very low polarities and vapor pressures, is limited, even after long sonication times.

This problem has been recently overcome by the methodology proposed by Ramos et al. ${ }^{18}$ using a microemulsion aqueous solution of the analyte in an apolar solvent. The advantage of microemulsions with respect to normal micelles is that the highly hydrophobic core is adequate for dissolving relatively high concentrations of hydrophobic molecules in the aggregate and also large organic molecules with dimensions approaching those of many micelles. ${ }^{19}$

In many microemulsions, the mass fraction of a solvent can be varied over a fairly wide range (e.g., $0-80 \%)$ without destruction of the monophase system. Although microemulsions offer more possibilities than normal micelles for the development of new analytical procedures, to date only a few applications have been developed. 20,21

Although the determination of carbaryl by chemical deoxygenation MS-RTP ${ }^{22}$ has been described recently, microemulsion room temperature phosphorimetry (ME-RTP) has been never used before for this purpose.

In order to obtain the optimum spectrophosphorimetric response, a statistical model was applied: type of central composite design. ${ }^{23}$ The project has been to evaluate the significance of each variable in addition to the interaction between variables that affects the phosphorescence of carbaryl.

In the present work, the applicability of ME-RTP has 
Table 1 A review of phosphorimetric methods for the quantitative determination of carbaryl

\begin{tabular}{lrc}
\hline Analytical method & Detection limit $/ \mathrm{ng} \mathrm{ml}^{-1}$ & Reference \\
\hline & & \\
Colorimetric & 120 & 24 \\
GC-fluorometric & 50 & 25 \\
Fluorometric & 100 & 26 \\
HPLC-fluorometric & 30 & 27 \\
Fluorometric & 200 & 28 \\
HPLC-photometric & 100 & 29 \\
HPLC-fluorometric & 40 & 6 \\
Photometric & 300 & 30 \\
LC-fluorometric & 50 & 31 \\
Phosphorimetric & 40 & 20 \\
Phosphorimetric & 25 & this work \\
\hline
\end{tabular}

been demonstrated by the succesful results obtained when the proposed method have been applied to different synthetic mixtures and soil samples.

\section{Experimental}

\section{Reagents and chemicals}

The solvents dichloromethane and 1-pentanol, the surfactant sodium dodecyl sulfate (SDS) (Sigma Chemical Co.), reagent grade thallium(I) nitrate and anhydrous sodium sulfite (Sigma Chemical Co.) and sulfuric acid (Sigma Chemical Co.) were used as received. Aqueous solutions were made with doubly distilled water. The sodium sulfite solutions were daily prepared and kept in tightly stopped containers.

Carbaryl (Fluka Chemie AG) was used without further purification. Microemulsion stock solutions were prepared by dissolving $5 \mathrm{mg}$ of carbaryl in $1 \mathrm{ml}$ of dichloromethane, adding $1 \mathrm{ml}$ of 1-pentanol and making up to $50 \mathrm{ml}$ with $0.5 \mathrm{M}$ SDS.

\section{Apparatus}

All recordings of uncorrected luminescence spectra and measurements of ME-RTP intensities were carried out with an Aminco Bowman series 2 luminescence spectrometer equipped with a $7 \mathrm{~W}$ pulsed xenon lamp. Measurements required a personal computer with $40 \mathrm{MB}$ hard disk, 4 MB RAM memory, 3.5-inch 1.44 MB floppy disk drive, VGA color monitor with VGA graphics adapter card, serial 2-button mouse, DOS 6.0, OS/2 version 2.0, and a GPIB (IEEE-488) interface card for computer instrument communication. The spectrometer was equipped with a thermostated cell holder.

\section{Software}

STATGRAPHICS Statistical Institution Edition Version 6.0. Inc. and Statistical Graphics Corporation 1992.

\section{Sample preparations and procedure}

Basic procedure. A $100 \mu \mathrm{l}$ aliquot of the carbaryl stock microemulsion, $0.64 \mathrm{ml}$ of $0.5 \mathrm{M} \mathrm{SDS}, 1 \mathrm{ml}$ of $0.25 \mathrm{M}$ thallium nitrate and $0.49 \mathrm{ml}$ of $0.1 \mathrm{M}$ sodium sulfite and $0.79 \mathrm{ml}$ of $0.02 \mathrm{M}$ sulfuric acid were introduced into a 10-ml standard flask and made up to volume with water. If a precipitate appears after the addition of the heavy atom salt, the flask was warmed until the precipitate disappeared, before the other reagents were added. After thorough mixing, the flask was placed in a water bath at $25 \pm 1^{\circ} \mathrm{C}$ for $10 \mathrm{~min}$. Standard $10-\mathrm{mm}$ fused silica cells are filled with this solution.

Phosphorescence intensities were measured at $490 \mathrm{~nm}$ with excitation at $292 \mathrm{~nm}$. Reagents blanks lacking carbaryl were prepared and measured following the same procedure.

Procedure for soil samples. The present method have been applied to soil samples from Gojar village (Granada, Spain). A certain quantity of carbaryl is added to $10 \mathrm{~g}$ of sample in such a way that the final concentration was included in the calibration graph. The samples were extracted twice with $30 \mathrm{ml}$ dichloromethane, filtering on vacuum, and washing the dry residue with $10 \mathrm{ml}$ dichloromethane. Both extracts are mixed and taken to dryness in a rotary evaporator at $40^{\circ} \mathrm{C}$.

The residue is diluted to $10 \mathrm{ml}$ with dichloromethane, $1 \mathrm{ml}$ is taken and $1 \mathrm{ml} \mathrm{1-pentanol} \mathrm{is} \mathrm{added,} \mathrm{diluting} \mathrm{the}$ mixture to $50 \mathrm{ml}$ with SDS $0.5 \mathrm{M}$. The basic procedure is applied to this solution (Note: thallium(I) salts and dichloromethane are very toxic).

\section{Results and Discussion}

Mixing dichloromethane, 1-pentanol and SDS aqueous solution results in the formation of a oil-in-water $(0 / w)$ microemulsion. In this microenvironment, phosphors such as carbaryl are protected and escape partially or entirely from quenching caused by collisional deactivation. For forming this special aggregate containing a hydrocarbon core, critical concentrations for the surfactant SDS as well as the proper proportions of the apolar solvent and the alcohol, should be carefully selected. However, an external heavy atom addition, together with the deoxygenation carried out by sodium sulfite, seems to be decisive in obtaining RTP.

\section{Optimization of experimental variables and spectral charac- teristics}

In order to achieve maximum sensitivity, the optimum conditions should be selected. The effect of each experimental variable and their interactions were investigated using four-variable, composite hypercube-star design. ${ }^{23}$

The variables used in this multivariate optimization were SDS, $\mathrm{TINO}_{3}, \mathrm{Na}_{2} \mathrm{SO}_{3}$ and $\mathrm{H}_{2} \mathrm{SO}_{4}$ concentrations. In order to have a forecast of high quality, we applied the 
Table 2 Experimental field for a design matrix: variables and carbaryl phosphorescence measurement

\begin{tabular}{|c|c|c|c|c|c|}
\hline No. & $\begin{array}{r}{[S D S] /} \\
10^{-2} \mathrm{M}\end{array}$ & $\begin{array}{c}{\left[\mathrm{TlNO}_{3}\right] /} \\
10^{-2} \mathrm{M}\end{array}$ & $\begin{array}{c}{\left[\mathrm{Na}_{2} \mathrm{SO}_{3}\right] /} \\
10^{-3} \mathrm{M}\end{array}$ & $\begin{array}{c}{\left[\mathrm{H}_{2} \mathrm{SO}_{4}\right] /} \\
10^{-3} \mathrm{M}\end{array}$ & $I_{\text {Phos }}$ \\
\hline 1 & 2.00 & 2.00 & 4.50 & 1.80 & 0.80 \\
\hline 2 & 2.00 & 3.00 & 4.50 & 1.80 & 0.74 \\
\hline 3 & 2.00 & 2.00 & 4.50 & 1.40 & 0.89 \\
\hline 4 & 4.00 & 3.00 & 4.50 & 1.40 & 0.91 \\
\hline 5 & 2.00 & 2.00 & 5.50 & 1.40 & 0.75 \\
\hline 6 & 4.00 & 2.00 & 5.50 & 1.40 & 0.68 \\
\hline 7 & 4.00 & 3.00 & 4.50 & 1.80 & 0.73 \\
\hline 8 & 4.00 & 2.00 & 4.50 & 1.40 & 0.88 \\
\hline 9 & 3.00 & 2.50 & 5.00 & 1.60 & 0.92 \\
\hline 10 & 4.00 & 2.00 & 5.50 & 1.80 & 0.89 \\
\hline 11 & 2.00 & 3.00 & 5.50 & 1.40 & 0.65 \\
\hline 12 & 4.00 & 3.00 & 5.50 & 1.40 & 0.73 \\
\hline 13 & 4.00 & 2.00 & 4.50 & 1.80 & 0.70 \\
\hline 14 & 2.00 & 3.00 & 4.50 & 1.40 & 0.90 \\
\hline 15 & 2.00 & 3.00 & 5.50 & 1.80 & 0.90 \\
\hline 16 & 4.00 & 3.00 & 5.50 & 1.80 & 0.89 \\
\hline 17 & 2.00 & 2.00 & 5.50 & 1.80 & 0.88 \\
\hline 18 & 9.42 & 2.50 & 5.00 & 1.60 & 0.87 \\
\hline 19 & 3.00 & 3.52 & 5.00 & 1.60 & 0.90 \\
\hline 20 & 5.06 & 2.50 & 5.00 & 1.60 & 0.90 \\
\hline 21 & 3.00 & 1.47 & 5.00 & 1.60 & 0.76 \\
\hline 22 & 3.00 & 2.50 & 5.00 & 1.60 & 0.94 \\
\hline 23 & 3.00 & 2.50 & 5.00 & 1.19 & 0.69 \\
\hline 24 & 3.00 & 2.50 & 5.00 & 2.01 & 0.78 \\
\hline 25 & 3.00 & 2.50 & 3.97 & 1.60 & 0.70 \\
\hline 26 & 3.00 & 2.50 & 6.03 & 1.60 & 0.68 \\
\hline
\end{tabular}

experimental matrix of the type composite blocked hypercube-star design. The 26 experiments dictated by the matrix are presented in detail in Table 2.

The results of this study (Table 2) show that the experimental response, as a function of the variables levels, can be approximated by a quadratic equation. One can conclude from the magntitude of the coefficients in this equation that the interaction between the variables is small. Therefore, terms that contain the interaction between variables would be important only at high values of the correspondent variables.

The maximum response is obtained with [SDS] of $3.20 \times 10^{-2} \mathrm{M},\left[\mathrm{TINO}_{3}\right]$ of $2.67 \times 10^{-2} \mathrm{M},\left[\mathrm{Na}_{2} \mathrm{SO}_{3}\right]$ of $4.94 \times$ $10^{-3} \mathrm{M}$ and $\left[\mathrm{H}_{2} \mathrm{SO}_{4}\right]$ of $1.59 \times 10^{-3} \mathrm{M}$. These concentrations were used as the working conditions, and selected for the rest of the experimental work.

The response surfaces of SDS and $\mathrm{TINO}_{3}, \mathrm{SDS}$ and $\mathrm{Na}_{2} \mathrm{SO}_{3}, \mathrm{SDS}$ and $\mathrm{H}_{2} \mathrm{SO}_{4}, \mathrm{TINO}_{3}$ and $\mathrm{Na}_{2} \mathrm{SO}_{3}, \mathrm{TINO}_{3}$ and $\mathrm{H}_{2} \mathrm{SO}_{4}$ and also $\mathrm{Na}_{2} \mathrm{SO}_{3}$ and $\mathrm{H}_{2} \mathrm{SO}_{4}$ at the optimum values obtained are represented in Fig. 1.

As can be deduced from these figures, there is a great stability in the phosphorescence response for a wide range of the micellar solution concentration, when varying the concentration of the deoxygenation compound and/or the external heavy atom (see Figs. 1a, 1b, 1c). But, as can be seen in Fig. 1f, there is a marked effect on carbaryl phosphorescence response when the sulfuric acid concentrations are varied in the solution in presence of different concentrations of the oxygen scavenger. As

$I_{\text {Phos: }}$ phosphorescence intensity.
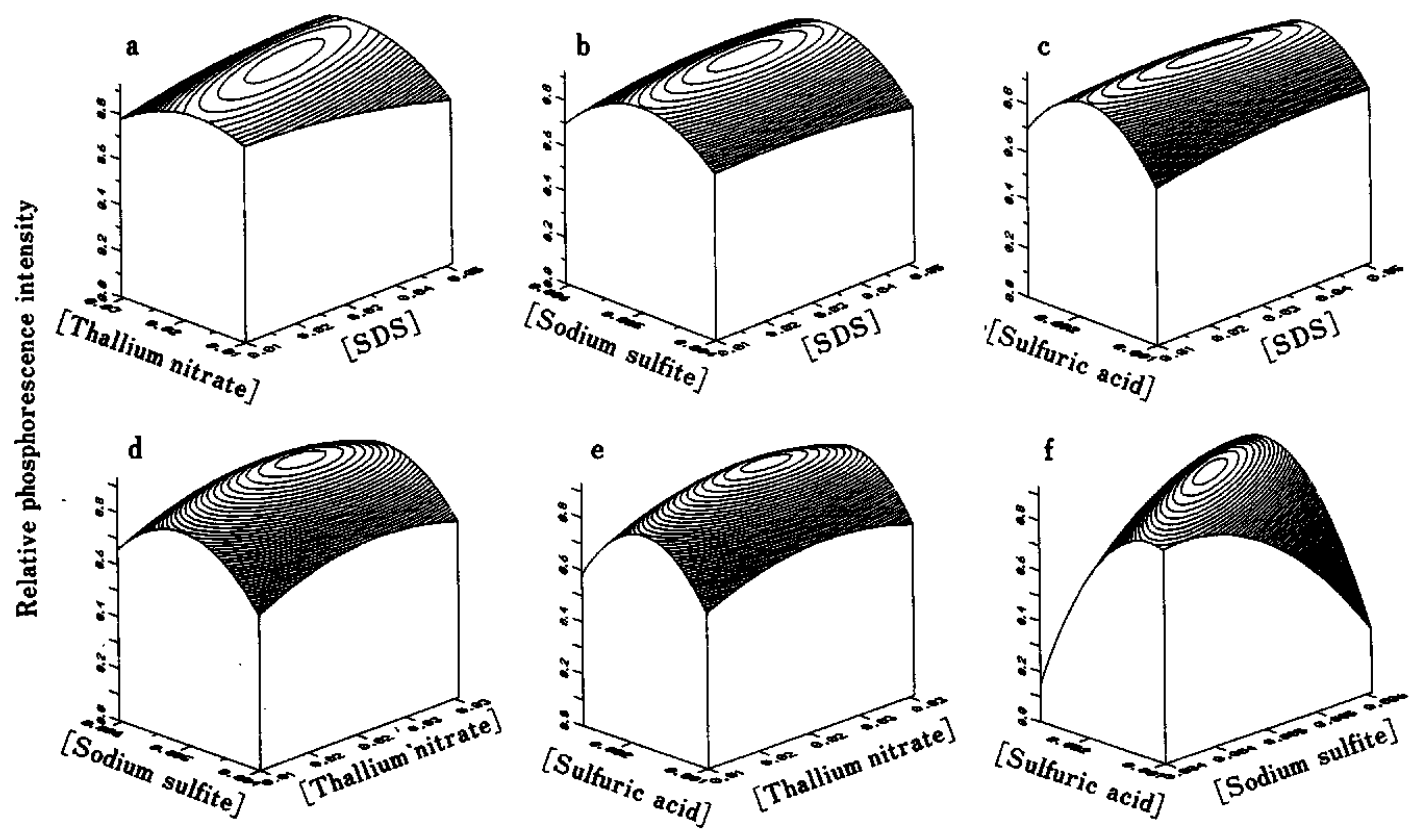

Fig. 1 Surface response of carbaryl for (a) SDS and $\mathrm{TlNO}_{3}$ concentrations at $\mathrm{Na}_{2} \mathrm{SO}_{3}$ and $\mathrm{H}_{2} \mathrm{SO}_{4}$ concentrations $4.94 \times 10^{-3} \mathrm{M}$ and $1.49 \times 10^{-3} \mathrm{M}$, respectively; (b) SDS and $\mathrm{Na}_{2} \mathrm{SO}_{3}$ concentrations at $\mathrm{TINO}_{3}$ and $\mathrm{H}_{2} \mathrm{SO}_{4}$ concentrations of $2.57 \times 10^{-2} \mathrm{M}$ and $1.59 \times 10^{-3} \mathrm{M}$, respectively; (c) SDS and $\mathrm{H}_{2} \mathrm{SO}_{4}$ concentrations at $\mathrm{TINO}_{3}$ and $\mathrm{Na}_{2} \mathrm{SO}_{3}$ concentrations of $2.57 \times 10^{-2} \mathrm{M}$ and $4.94 \times 10^{-3} \mathrm{M}$, respectively; (d) $\mathrm{TlNO}_{3}$ and $\mathrm{Na}_{2} \mathrm{SO}_{3}$ concentrations at SDS and $\mathrm{H}_{2} \mathrm{SO}_{4}$ concentrations of $3.20 \times 10^{-2} \mathrm{M}$ and $1.59 \times$ $10^{-3} \mathrm{M}$, respectively; (e) $\mathrm{TlNO}_{3}$ and $\mathrm{H}_{2} \mathrm{SO}_{4}$ concentrations at SDS and $\mathrm{Na}_{2} \mathrm{SO}_{3}$ concentrations of $3.20 \times 10^{-2} \mathrm{M}$ and $4.94 \times 10^{-3} \mathrm{M}$, respectively and (f) $\mathrm{Na}_{2} \mathrm{SO}_{3}$ and $\mathrm{H}_{2} \mathrm{SO}_{4}$ concentrations at SDS and $\mathrm{TINO}_{3}$ concentrations of $3.20 \times 10^{-2} \mathrm{M}$ and $2.57 \times 10^{-2} \mathrm{M}$, respectively. 
Table 3 Optimum instrumental parameters

\begin{tabular}{lc} 
Fluorescence wavelengths $(\mathrm{ex} / \mathrm{em})$ & $292 / 337 \mathrm{~nm}$ \\
Phosphorescence wavelengths $(\mathrm{ex} / \mathrm{em})$ & $292 / 490 \mathrm{~nm}$ \\
Slits $(\mathrm{ex} / \mathrm{em})$ & $16 / 16 \mathrm{~nm}$ \\
Minimum period pulse & $5 \mathrm{~ms}$ \\
Scanning speed & $2 \mathrm{~nm} / \mathrm{s}$ \\
Decay time & $200 \mu \mathrm{s}$ \\
Gate time & $1000 \mu \mathrm{s}$ \\
Detector sensitivity & $1100 \mathrm{~V}$ \\
\hline
\end{tabular}

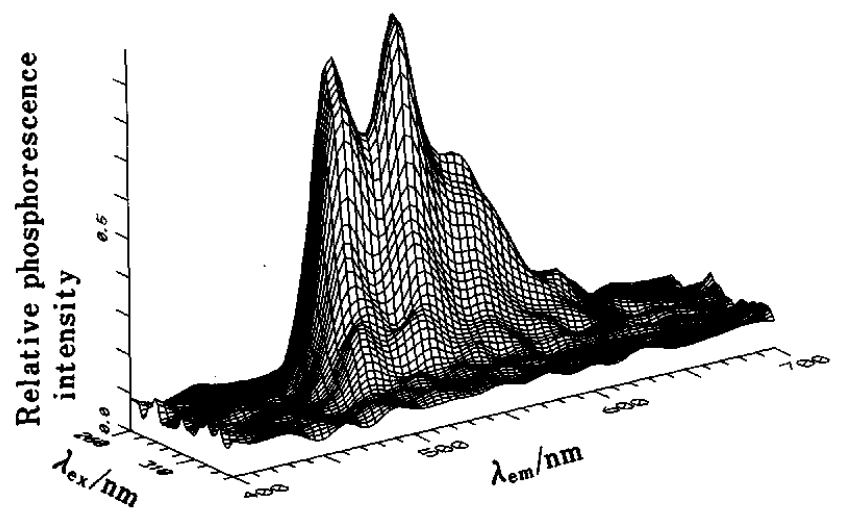

Fig. 2 Projected three-dimensional spectrum of carbaryl. ppb carbaryl $=400 \mathrm{ng} \mathrm{ml}^{-1},[\mathrm{SDS}]=3.20 \times 10^{-2} \mathrm{M},\left[\mathrm{TlNO}_{3}\right]=$ $2.57 \times 10^{-2} \mathrm{M},\left[\mathrm{Na}_{2} \mathrm{SO}_{3}\right]=4.94 \times 10^{-3} \mathrm{M},\left[\mathrm{H}_{2} \mathrm{SO}_{4}\right]=1.59 \times 10^{-3}$ M; emission 400 - $700 \mathrm{~nm}$, excitation 250 - $350 \mathrm{~nm}$; scanning speed $2 \mathrm{~nm} / \mathrm{s}$; decay time $200 \mu \mathrm{s}$; gate time $1000 \mu \mathrm{s}$; detector sensitivity, $1100 \mathrm{~V}$.

a result of these experiments, the optimum working conditions to obtain the highest phosphorescence response were selected.

As for the optimum instrumental parameters for RTP carbaryl determination, the data selected are summarized in Table 3.

The total luminescence spectra of carbaryl in a dichloromethane/1-pentanol emulsion agent in SDS micelles, with $\mathrm{TlNO}_{3}$ as heavy atom and $\mathrm{Na}_{2} \mathrm{SO}_{3}$ as oxygen scavenger, is shown in Fig. 2.

The results indicate that stable and homogeneous microemulsions can be obtained in the range $0.5-3 \%$ (v/v) dichloromethane or 1-pentanol. Hence $2 \%$ dichloromethane and 1-pentanol were used throughout this work. After dilution, the dichloromethane and 1pentanol concentrations in the final solutions were $0.02 \%$. Under these conditions, stable and very intense RTP can be obtained.

The RTP intensities decrease almost linearly with increase in temperature. The decrease is greater in a microemulsion system than in a micelle system when the temperature increases by $5^{\circ} \mathrm{C}$. The residual fluorescence intensities decrease slightly with increase in temperature. These effects are mainly related to molecular thermal motion and intermolecular energy conversion.
Table 4 Effect of foreign species on the determination of $400 \mathrm{ng} \mathrm{ml}^{-1}$ carbaryl

\begin{tabular}{lc}
\hline \multicolumn{1}{c}{ Foreign species } & Tolerance level/ng ml-1 \\
\hline$p$-Chlorophenoxyacetic acid & $>40000$ \\
2,4-Dichlorophenoxyacetic acid & $>40000$ \\
Carbendazime & $>30000$ \\
2-(4-Thiazolyl)benzimidazole & $>400$ \\
2-Aminophenol & $>400$ \\
3-Amino-1,2,4-triazole & $>400$ \\
$\alpha$-Naphthol & $>40$ \\
\hline
\end{tabular}

The molecular thermal motion causes collisional deactivation of the phosphors. A temperature of $25 \pm 1^{\circ} \mathrm{C}$ was selected for the rest of the experimental work.

\section{Validation of the method}

The method was tested for linearity, precision, reproducibility and specificity. Phosphorescence response was linear in relation to the concentration of carbaryl over the range $80-600 \mathrm{ng} \mathrm{ml}^{-1}$ calculated in the final solution.

The regression equation was

$$
P=0.104+2.1 \times 10^{-3} C
$$

where $P$ is the phosphorescence intensity and $C$ the concentration of carbaryl in $\mathrm{ng} \mathrm{ml}^{-1}$. The correlation coefficient $r=0.999(n=7)$, indicating excellent linearity. A detection limit of $23.8 \mathrm{ng} \mathrm{ml}^{-1}$ was determined.

The precision of the method was determined at two different concentrations. The relative standard deviation (RSD) $(n=7)$ was 3.44 and $1.48 \%$ for concentrations of carbaryl of 200 and $500 \mathrm{ng} \mathrm{ml}^{-1}$, respectively.

The microemulsion room-temperature phosphorescence method proposed was applied to the analysis of carbaryl in the presence of different plant growth regulators and insecticides. Table 4 summarizes the results calculated from the calibration graph.

The phosphorescence spectra were always found to be identical to the corresponding carbaryl spectra.

\section{Application of the method to soil samples}

A soil sample from Gójar village (Granada, Spain) was spiked with carbaryl by adding appropriate volumes of a standard solution. Different recovery experiments in the spiked soil samples were performed. Samples of carbaryl containing $400 \mathrm{ng} \mathrm{ml}^{-1}$ were analyzed. A mean value of $95.8 \%(n=3)$, with an RSD of $2.55 \%$, has been obtained.

The authors gratefully acknowledge Dirección General de Universidades e Investigación de la Junta de Andalucia for the financed support by a grant. 


\section{References}

1. C. S. P. Sastry, D. Vigaya and D. S. Manala, Analyst [London], 112, 75 (1987).

2. Z. C. Cohem, J. H. A. Ruzicka and B. B. Wheala, $J$. Chromatogr., 49, 215 (1970).

3. W. H. Gutenmann and D. J. Lisk, J. Agric. Food Chem., 13, 48 (1965).

4. L. I. Butler and L. M. Mcdonough, J. Assoc. Off. Anal. Chem., 53, 495 (1970).

5. Z. Janke and F. Chengguang, Fenxi Ceshi Tongbao, 4, 24 (1987).

6. M. De. Bererdmis and W. A. Wargin, J. Chromatogr., 246, 89 (1982).

7. J. Keiser, K. Kirby and F. Tremmel, J. Chromatogr., 259, 186 (1983).

8. J. A. Coburn, B. D. Ripley and A. S. Y. Chau, J. Assoc. Off. Anal. Chem., 159, 188 (1976).

9. S. K. Handa and A. K. Dikshit, Analyst [London], 104, 1185 (1979).

10. K. Kalyanasundaram, F. Grieser and J. K. Thomas, Chem. Phys. Lett., 51, 501 (1977).

11. M. Skrilec and L. J. Cline Love, J. Phys. Chem., 85, 2047 (1981).

12. A. Sanz-Medel, P. L. Martínez-García and M. E. DíazGarcía, Anal. Chem., 59, 784 (1987).

13. N. E. Nugara and A. D. King Jr., Anal. Chem., 61, 1431 (1989).

14. M. E. Díaz-García and A. Sanz-Medel, Anal. Chem., 58, 1436 (1986).

15. Y. S. Wei, C. S. Liu and S. S. Zhang, Fenxi Huaxue, 18, $228(1990)$.

16. W. J. Jin and C. S. Liu, Microchem. J., 48, 94 (1993).
17. Y.S. Wei, W. I. Jin, R. H. Zhu, C. S. Liu and S. S. Zhang, Talanta, 41, 1617 (1994).

18. G. R. Ramos, I. M. Khasawneh, M. L. García-ÁlvarezCoque and J. D. Winefordner, Talanta, 35, 41 (1988).

19. A. Muñoz de la Peña, T. T. Ndou and I. M. Warner, "Spectroscopic Studies in Organized Media in Advances in Multidimensional Luminiscence", Vol. 2, pp. 1-18, JAI Press Inc., 1993.

20. W. Yansheng, J. Weijun, Z. Rohua, L. Changsong and Z. Sushe, Talanta, 41, 1617 (1994).

21. W. J. Jin, Y. S. Wei, W. S. Duan and C. S. Liu, Anal. Chim. Acta, 287, 95 (1994).

22. C. Cruces Blanco, A. Segura Carreterro and A. Fernández Gutiérrez, Anal. Chim. Acta, in press.

23. G. E. P. Box, W. G. Hunter and J. S. Hunter, "Statistic for Experiments", Chap. 15, Wiley, New York, 1978.

24. W. R. Benson and J. M. Finocchiaro, J. Assoc. Off. Anal. Chem., 48, 676 (1965).

25. R. J. Argauer, H. Shimanuki and C. Alvárez, J. Agric. Food. Chem., 18, 688 (1970).

26. R. J. Argauer and W. Bontoyan, J. Assoc. Off. Anal. Chem., 53, 1166 (1970).

27. R. J. Argauer and J. D. Warthen Jr., Anal. Chem., 47, 2472 (1975).

28. M. J. Larkin and M. J. Day, J. Agric. Food Anal. Chem., 25, 211 (1979).

29. G. R. Pieper, Bull. Environ. Contam. Toxicol., 22, 167 (1979).

30. K. M. Appaiah, R. Ramakrishna, R. R. Subbarao and $O$. Kapur, J. Assoc. Off. Anal. Chem., 65, 32 (1982).

31. R. T. Krause, J. Assoc. Off. Anal. Chem., 68, 734 (1985).

(Received March 4, 1996)

(Accepted May 17, 1996) 